\title{
THE RISE AND FALL OF THE WEALTH OF NATIONS Factor-Price Equalization Theorem Revisited ${ }^{*}$
}

\section{OKTAY YENAL}

My generation was born into an era when the world was divided into haves and have-nots, the former taking for granted their continuing and increasing prosperity, and the latter not entertaining much hope of catching up. In the last few years we have experienced a basic shake-up in our beliefs and analyses. The economic supremacy of the West is being challenged not only by Japan but also by the ASEAN NICs - South Korea, Taiwan, Hong Kong, Singapore, Thailand and Malaysia. If the dynamism of China continues at the rate it has been during the past decade, it will be a major contender by the beginning of the 21 st century. The optimism has become contagious. Many countries like Indonesia, Mexico, Brazil, Chile and Turkey are also feeling more confident that they have a good chance of cathing up with the West.

This optimism about the reduction of the gap between the living standards of the rich and the poor countries does not emanate merely from improved prospects in some developing countries but also from the lackluster prospects in industrialized countries. The continuing recession - slow growth and high unemployment - in the West appears increasingly as part of a historical trend rather than a mere cyclical disturbance even though most analysts still talk of a delayed upturn or recovery. More careful observers have pointed to the process of disindustrialization that has been occurring in

\footnotetext{
"Read at the Rajiv Gandhi Institute for Contemporary Studies, New Delhi, 16 June 1994, when the author was the Chief of Mission of the World Bank in India.
} 
the Western countries, especially in the U.S. ${ }^{1}$ The share of manufacturing in total value added is going down in the U.S. as well as in Europe. Some economists do not see much to worry about in this trend drawing attention to the rising share of services. But there are increasing signs that the growth of services is also affected when the goods production base stagnates.

The short or medium term trends of economic growth in each country or region have been explained by the traditional theories that focus on growth determinants such as investments - both physical and human - and economic policies. But more fundamental forces appear to be in action for determining long term trends. For a long period in history, the rise and fall of economic powers were associated with the richness of natural endowments including the climate - and military might. Trade routes connecting major sources and users of primary and manufactured goods were always considered important but it was left to Adam Smith and the Classical economists to highlight and define more vigorously the benefits of trade among countries. Up to the eighteenth century the opening of new trade routes and disruption of the old ones explained to a large degree the rise and fall of the economic fortunes of the nations.

While highlighting the more immediate growth determinants and constraints, these types of explanations do not provide strong clues as to why Europe and North America achieved high levels of prosperity during the last two centuries and why others did not. Nor are causes of relative shift of economic gravity from the West to the East easier to understand using these tools of analysis. This essay aims at analyzing the more basic causes of these trends:

(a) Why did the gap between the industrialised countries and the rest of the world widen so much over the past two centuries?

(b) Why did international trade not help to narrow this gap?

(c) What are the implications of much faster diffusion of technologies for the future prospects of the rich and the poor countries?

It has become increasingly evident that one of the most significant continuities in social and economic life, linking the past two centuries to the next, will be the process of industrialization. This connotes industrialization in a broad sense, that is, the techniccal progress which enriches the transformation of human and natural endowments to better serve the needs

\footnotetext{
1 "Deindustrialization is the common faith of advanced industrial economies". Robert Solov, "Blame the Foreigner", The New York Review of Books, 16 December 1993.
} 
and wants of societies. In this respect it covers, in addition to industry proper, the technical progress embodied in agriculture and services as well.

Technical progress has been a facet of human history from the very beginning. The discovery of various metals, energy sources and the inventions of tools especially the wheel, were no doubt comparable in their relative welfare contributions to the technological advances of recent times. But what distinguishes the last two centuries has been the quantum jump in the utilization of energy sources, raw materials and capital equipment to produce a vast variety of manufactured items. ${ }^{2}$ No only did the industrial revolution increase the importance of production compared to trade as a source of value added, but commerce itself became more dependent on industry than on natural resources, especially in value terms. Technological advances were central to both industrialization and to the speed of development. $^{3}$

The countries which first achieved technical progress or the indusrial revolution and those which joined the club early on reaped the benefits of productivity increase manifold over what their natural resource or unskilled human endowments would have yielded. ${ }^{4}$ Through this process, countries, and within countries groups of populations, enjoyed the benefits of technical progress, of course supplemented also by the accumulation of assets. In simple language they became rich. In terms of per capita income growth, the experience of Western Europe and North America during the nineteenth century and the first half of the twentieth century was unique. The haves and have-nots dichotomy of the world that our generation inherited was, to a very large extent, the result of differences in technical progress.

\footnotetext{
2"What distinguishes the world since the industrial revolution from the world before is the systematic, regular and progressive application of science and technology to the production of goods and services. The scientific revolution, in all its consequences, is the element in the equation of history that distinguishes early modern Europe from all previous periods of expansion." W.W. Rostow, How It All Began.

3 "Virtually all scholars of productivity growth now agree on the central role of technological advance". Richard R. Nelson, "Research on Productivity Growth and Productivity Differences: Dead Ends and New Departures", Journal of Economic Literature, Vol XIX (Sept. 1981).

4 "The technological inventions of the last few centuries are the prime factors that make it possible for a country to shift from low levels of income per capita to high levels of income per head. It is only because of the vast increase in technical knowledge, especially with respect to the utilization of non-animal energy sources, that we are able to increase output per man considerably". H. Leibenstein, "Technical Progress and Development", in W.W. Rostow (ed.), The Economics of Take-off into Sustained Growth.
} 
The recognition of the gap that exists between the living standards of countries as an economic issue, however, is a more recent phenomenon and was hardly in the public consciousness before the Second World War. In the century and a half of industrialization preceding the Second World War, the relative poverty of a large part of the world under colonial rule or in similar backward situations was perceived as a topic in political development or as issues pertaining to people who were in their pre-civilized state. And the differences in living standards appeared as a civilization gap rather than an economic phenomenon. An example of this mind set is reflected, for example, in the work of a liberal such as John Stuart Mill when he talks of "those backward states of society in which the race itself may be considered in its nonage". 5

Recognition of the prosperity differentials among nations as an economic issue after the Second World War gave rise to much thinking and theorising on development economics that we are familiar with. The role of international trade was re-emphasized and codified. Great importance was attached to capital accumulation and investment choice. Physical and human infrastructure and appropriate government policies were also highlighted as important variables of development models. The role of technology was not totally absent from the growth models but it was usually treated -mostly implicitly - as embodied in human capital. Some attempts by economists to see technical progress separately from social evolution were not totally absent as in the case of Schumpeter's theory of economic development where he put the emphasis on "entrepreneurial innovation". But even this concept was conceived as deeply rooted in the human development of the country. The thought that it could be exported to other countries was not central to these paradigms.

My generation was taught to believe that technical progress was an organic process and that the industrial revolution in the West was the culmination of centuries of accumulation of science, basic research and human attitudes, nurtured in a milieu of Calvinist ethics and that its replication in the less developed world be a matter of many generations, if at all feasible. It appeared for a long while that catching up with the West was an empty dream since the gap vis-a-vis industrialized countries would continue widening. Hence, those concerned with the problems of the less developed world were resigned to setting their strategies at more modest goals of reducing poverty but not even thinking of challenging the economic supremacy of the West.

Pure economic theory produced some clues that could challenge this fatalistic attitude. One such important clue came from the Factor Price Equalization Theorem. Bertil Ohlin argued as early as 1933 that although free

\footnotetext{
5John Stuart Mill, On Liberty, p. 13.
} 
mobility of factor inputs in international trade will equalize factor returns all the way, free mobility of goods can serve only to move factor prices toward (but not all the way to) factor equalization. Paul Samuelson was not satisfied with this proposition. ${ }^{6} \mathrm{He}$ demonstrated that under certain assumptions such as zero transport costs, no complete specialization in either country and with the same laws of knowledge operative everywhere, mobility of goods would result in full factor price equalization even when factors were not mobile between countries. $^{7}$

The experience of a century or more, however, had shown that this had not happened in a big way. The factor prices among the poor and the rich countries had not converged. On the contrary, they had moved further apart. Realising this, Samuelson had prefaced his seminal article by a caveat: "I cannot pretend to present a balanced appraisal of the bearing of this analysis upon interpreting the actual world, because my own mind is not made up in this question: on the one hand, I think it would be folly to come to any startling conclusions on the basis of so simplified a model and such abstract reasoning; but on the other hand, strong simple cases often point the way to an element of truth present in a complex situation."

There were, however, some examples of factor price equalization which had taken place. The industrial revolütion, which started essentially in England, jumped to France, Germany, the United States and later to Japan. But Europe and the United States were often seen as offshoots of England, and Japan was treated as a special case. Until the recent couple of decades, the increasing gap between the real wages of these countries and the rest of the world for almost two centuries when international trade was largely unrestricted and capital was quite mobile presented at least a major puzzle about, if not an empirical negation of the factor-price equalization theorem.

${ }^{6}$ P. A. Samuelson, "International Trade and the Equalization of Factor Prices", Economic Journal, (June 1948).

${ }^{7}$ An interesting story connected with this is worth repeating. When Professor Lionel Robbins saw this article in print, he remembered a paper that one of his former students, Abba Lerner, had presented in his seminar in 1933. He dug out the paper and published it in Econometrica. Like many important theorems, it looks like simple common sense after it has been thought through. If wage differentials within a country are minor, why should there be such large differences in real wages across countries? Schumpeter had argued that profits which were returns to entrepreneurial innovation would be wiped out through competition, and the Samuelson-Lerner Theorem showed that free mobility of goods (competition) would equalize factor prices even when factors were immobile.

${ }^{8}$ P. A. Samuelson, "International Factor-Price Equalization Once Again", Economic Journal, 1949. 
Samuelson himself expressed, many years later, further doubts about the relevance of his famous theorem to the real world. In an article entitled "Ohlin Was Right", he said: "Men receive lower wages in some countries than others for a variety of reasons - because their effective know-how is limited and manner of their being combined with other productive factors is not optimal. In the face of hard facts it would be rash to consider the existing distribution of population to be optimal in any sense, or to regard free trade as a panacea for the present geographical inequalities."

The developments of the recent decades, however, have changed this perception and may warrant an article that would be entitled "Samuelson and Lerner Were Right After All." Following Japan, we have witnessed the rapid development of other East Asian countries-Korea, Taiwan, Hong Kong, Singapore, Thailand, Malaysia and China. In all these countries the real wages have risen at very high rates. Real wages have also increased significantly in many other developing countries. Parallel with this, the growth rate has slowed down in the industrial West. So, after all, a process of factor equalization is taking place.

Both the absence of factor price equalization trends in the past two centuries and the emergence of these tendencies in the recent past have a great deal to do with the transfer of technology. Indeed, a crucial assumption of the factor-price equalization theorem, though not attracting much attention at the time, was that "the same laws of knowledge were operative everywhere" (Samuelson) or that "the same technical knowledge was available in both countries" (Lerner). Both the limited transmission of industrialization can be explained, at one level, by the major change that has taken place in the speed of technology transfer. ${ }^{10}$

Accelerated speed of technology transfer came about mostly as a by product of the communications revolution, which was itself a result of technological progress. Dramatic inventions and innovations in the communications technology have introduced a quantum jump in the diffusion of technical know-how, qualitatively different from what was the case in the past. On the results side, it took more than 50-60 years for the other countries to learn from the United States how to manufacture automobiles whereas the monopoly on the computer technology hardly lasted $15-20$ years. Not only have Japan, Hong Kong, Taiwan and Singapore learnt how to

${ }^{9}$ P.A. Samuelson,"Ohlin Was Right", Swedish Journal of Economics, 1971.

10"The postwar international transfer of technology among advanced countries and between advanced countries and less developed countries through technology exports was without historical precedent," Miyohei Shinohara, Industrial Growth, Trade and Dynamic Patterns in the Japanese Economy, (1982). 
imitate the latest processes of modern technology, but they have improved the quality of Western products in many areas. An interesting example of competitive labour markets even in the absence of labour mobility is the accounting and auditing work which gets done by the Indians for the American companies working through computer networks, without even leaving Calcutta for a day!

These experiences bring in a sense of self confidence to and open up new horizons for the under-developed countries. Increasingly, the analysts no longer look at the prerequisites of industrial revolution as the product of cultural evolutions spanning centuries, but of learning efforts which can be accomplished in a short time. Replicating modern industrial techniques is both easy and can be fast - perhaps as argued many years ago by Arthur Lewis, easier and faster than adopting new agricultural skills. Many East Asian countries have achieved major industrial transformations in almost one generation, and China is also moving fast on this route.

The interesting phenomenon of our day is not only that the learning process has become much faster pulling up the real wages in many developing countries - a process widely perceived and analyzed in recent years - but, equally important, that the factor-price equalization process is putting pressure on the real wages in the West to fall - an implication of the process still not fully recognized. The discussion of economic development has usually been in trems of catching up, that is, rising incomes in developing countries towards the higher levels in industrialized countries. But there is nothing in the theorem to rule out the symmetry of the factor equalization process, that is adjustment taking place partly by rising real wages in the developing countries and partly through falling real wages in advanced countries. This also follows from common sense. Given the high skill and technology content of many items of manufacturing and the trend towards a much faster technology transfer (learning process) the differential costs of manufactured items between countries will tend to reflect relative levels of real wages. If this is true to a large extent, is it all surprising that the goods manufactured in the developing countries with the same techniques but with labor whose real wages are 30-40 times lower than the real wages in advanced countries will present a severe competition to the industry of the latter?

These observations have far reaching implications for both the rich and the poor countries. The rich countries are becoming increasingly aware of the threat to them that comes from the rapid globalization of technology. Questions are being raised about the validity of the classical premise that free trade benefits all parties. Some argue that the static comparative advantage models may not hold in a rapidly changing world where increasing returns, steeper learning functions or, as proposed in this essay, faster transfer of technology have become important. Thus, the interventionist argument 
promoted by the so called "new trade theory",11 the "boomerang effect" elaborated by Shinahora ${ }^{12}$ and the characterization of trade between U.S. and Japan as a zero-sum game by Lester Thurow all direct our attention to the erosion of technology induced rents in the advanced countries. The stiff competition comes from the less advanced countries that are acquiring the know-how at a rapid pace and combining it with cheap labour.

With hindsight, one can argue that this is not a new phenomenon. For example, Shinahora says: "Most probably it (the boomerang effect) was powerfully at work when Germany and Japan began to challenge British economic supremacy, and also when the United States took over world economic hegemony from Britain. It is the turn of the U.S. now to feel the pain of the boomerang effect in relation to Japan. The U.S. is suffering the consequences of the know-how it itself exported. In fact, the international transfer of technology is always accompanied by the boomerang effect.".13 But in the last two decades the speed and the spread of technology transfer has become more global and pronounced.

The repercussions of the loss of technological superiority are noticeable not only on the factory floor. The import of cheaper cars, electronics or garments, in the first instance, appear to threaten only the high wage employment in localities such as Detroit, Silicon Valley or Manchester. The industrial workers are, no doubt, the direct casualties. But the rents of early technological advance and the monopoly surpluses from it did not accrue only to the factory workers and capitalists but permeated to the high salaries of white collar employees crowding the skyscrapers of the Western cities, five star hotels and first class lounges all over the world. These high earnings are also being threatened as already observed by the shrinking job markets in the Western countries. This is why the fact of rising shares of services in the total value added seen in developed countries provides little consolation because the services are not independent of the rents of technology and the manufacturing base.

Under these circumstances it is not surprising that the protectionist sentiments and efforts have been intensifying in advanced countries. These sentiments arise not only from the pressures of business which suffer but from the intuitive realizations of the politicians - as opposed to economists - that, given the loss of technological monopoly, the free trade

${ }^{11}$ The new trade theory puts less emphasis on the changed dynamics of technology transfer and more on market imperfections. Hence the need for industrial policy does not distinguish much between the more and less developed while the emphasis on technology tranfer introduces opposite implications for them.

12 Shinahora, op cit.

13 Ibid., p. 64. 
system does not amount to a plus sum game. The implications of the classical trade theory could still be valid with trading countries being better off to specialize in their areas of comparative (not necessarily absolute advantage) but this would not be sufficient to guarantee the advanced countries significantly higher real wages in industry. This is why free trade in today's dynamic world of rapid technology transfers, in the absence of complete specialization, increasingly exhibits the characteristics of a zero sum game. For each winner there is a loser and the winners are likely to be the countries that can combine universal technologies with cheap labour.

The defensive actions of the advanced countries have taken the forms of formal or informal trade barriers, the shift of enterprises to the countries with cheap labor and the creation or modification of trading blocks. The effort to increase trade barriers has not succeeded as much as some have feared because of the pressures coming from majority constituencies of consumers not ready to give up cheaper and sometimes better quality goods. The shift of plants to low wage countries is a way out for firms but not a panacea to the loss of employment opportunities in advanced countries or the pressure on their real wages. The trading blocks approach will also not provide an effective defence against the competition coming from the low wage countries. To the extent that such groupings include both advanced and less developed countries - like the North American Free Trade Area - they will speed up technology transfer with costs to the former and benefits to the latter. When the trading block is essentially a club of the early arrivers at industrial revolution - like the European Economic Community - the block members will continue to face the competition from the low wage countries. The members of such trading blocks can be likened to people, caught in a fast flowing river, who hope to slow down their drift by holding hands.

Protectionist sentiments have not succeeded so far in increasing the trade barriers to any significant degree. Nor should we expect protectionism to increase to any substantial degree. ${ }^{14}$ Cheaper goods have an attraction to the masses of consumers who will, in general, vote down the defenders of minority interests. Even if trade protection increases, it will neither stop the erosion of real wages in the developed countries nor stop the rise in developing ones. The more likely scenario is that we shall see various experiments with defensive adjustment programs to slow down the process.

14 "The myth (of increasing protection) has also prevented the economists from focusing on the phenomena which in reality marked the trade era in the 1980 s, namely, the commercial revolution which raised the developing countries to major players in manufacturers markets, and greatly contributed to depressing demand for labour in industrialized countries." Janet Baneth, unpublished memo. 
On the other hand, the revolution in information and technology dissemination provides a great opportunity for the less developed countries. First, this new era presents an opportunity for the less developed countries and among them those with cheaper labor. One hears of the 1980's being the golden age when the world export growth rate was high and when many East Asian countries took advantage of this so-called export led growth. According to this line of thinking, some countries - i.e. in South Asia and Africa- as it were, "missed the train". If the analysis above regarding the process of factor-price equalization is plausible, this pessimism is unwarranted; there exist and will continue to exist opportunities for countries of low wages to achieve major improvements in their standards of living. As observed above, some have already grasped this opportunity and achieved spectacular growth and poverty reduction in a short time. But even this new revolution will not help the countries which do not have the basic preparation for benefitting from it. Prerequisites for benefitting from technology transfer include, at the minimum, (a) the basic institutions of governance - law and order and some degree of social compact, (b) openness to global markets and technologies and (c) an educated work force. ${ }^{15}$ Even without having the basic research and richness of basic inventions, poor countries can go a long way by adopting efficient technologies and combining them with their cheap labor.

It is encouraging to see that increasing numbers of the less developed countries are realizing the folly of segregating their economies from the global economy. The observations above suggest that the haves have more reason to conserve what they possess than the have-nots who should be open to every opportunity. But the crucial role of education is still not fully appreciated in many parts of the world. In countries where the overall level of education is very poor as in some parts of Africa, no amount of opening up or getting the prices right or fiscal discipline will produce a perceptible or sustainable growth momentum. There are also countries of vast populations as in South Asia where a small (relative to population) cadre of the well educated class has been brought up while seriously neglecting basic education for more than half of the total population. In these countries, while some islands of development are taking place or will occur soon, this will not be sufficient for uplifting significantly the living standards of the illiterate majority of the population. Those who have little faith in the trickle down theories have a valid point when it comes to the spread of prosperity to those

15 "We need to know what was the minimum social accompaniment and technical adjustment necessary if a country was to take advantage of the stock of potential innovations available in the modern world as in the past. One essential prerequisite was apparently a minimal literacy. Another was the minimal scale of enterprise necessary for engineering reasons. A third was that work should be allocated in terms of efficiency in performance and not for family connections." S. Kuznets in W.W. Rostow (ed.), The Economics of Take-Off into Sustained Growth. 
who are, as J.S. Mill called them, in the nogage of development. There is no factor which correlates better with the growth rate of economies as an explanatory variable than basic education level. It is, therefore, no wonder that the East Asian countries going through their industrial revolution are also the most educated and literate as it happened in Europe two centuries ago. This hypothesis may also provide at least a partial explanation to a historical puzzle. The author has often wondered why international trade, which was completely free in the eighteenth and the twentieth centuries, did not act as a transmitter of the industrial revolution to Turkey (or to India). The reason evidently lies in the absence of the minimum prerequisites.

In conclusion, it appears that the communication revolution has ushered in a second industrial revolution through the rapid spread of learning. Many implications as highlighted above are of great relevance for the future trends of the relative wealth of nations. While the importance of the longterm tendencies and the opportunities that these present for the poorer countries cannot be exaggerated, the negative effects on the real incomes of the advanced countries will be gradual. The advantages of centuries of wealth, modern science, technological advance, and well established institutions will keep Europe, for some decades to come, amongst the wealthiest nations in the world. In addition to the old world heritages, the United States has the added advantage of vast natural resources, and Japan will benefit from its very cohesive industrial work culture. These are also the countries where populations do not grow or grow at a very slow pace although the immigration from the poorer countries and the high population growth of the immigrant minorities in these countries will present increasing problems. However, while the decline of real incomes will take a long time, the problems created by adjustments in this direction will dominate the content of their economic policies in the next few decades. The process predicted by the factor-price equalization theorem is taking place. It will not be able to change the relative prosperity of the nations overnight but the directions of relative change are irreversible and the opportunities are there for the poor nations who have the will to change. 